\title{
DIVERSIDADE GENÉTICA ENTRE GENÓTIPOS COMERCIAIS DE MARACUJAZEIRO- AMARELO (Passiflora edulis f. flavicarpa) E ENTRE ESPÉCIES DE PASSIFLORAS NATIVAS DETERMINADA POR MARCADORES RAPD ${ }^{1}$
}

\author{
ALEXANDRE PIO VIANA², TELMA NAIR SANTANA PEREIRA ${ }^{2}$, MESSIAS GONZAGA PEREIRA², MARGARETE MA- \\ GALHÃES DE SOUZA ${ }^{3}$, JOSÉ FRANCISCO MARTINEZ MALDONADO ${ }^{4}$, ANTÔNIO TEIXEIRA DO AMARAL JÚNIOR ${ }^{2}$
}

RESUMO -A diversidade genética entre genótipos de maracujazeiro amarelo foi avaliada por meio de marcadores genéticos de DNA tipo RAPD. Para tanto, materiais genéticos foram coletados em populações comerciais em regiões tradicionais de fruticultura da Região Norte Fluminense (Itaperuna, São Francisco do Itabapoana, Campos dos Goytacazes). Foi também estimada a diversidade entre a espécie cultivada (Passiflora edulis f. flavicarpa Deg.) e espécies relacionadas no gênero, P. alata, P. giberti, P. cincinnata, P. foetida, P. edulis. P. maliformes, P. mucronata, P. suberosa, P. malacophylla. Para o estudo dos acessos de maracujá amarelo não foi verificada expressiva diversidade genética; as populações se distribuíram conforme sua origem, sendo que os indivíduos coletados em São Francisco do Itabapoana apresentaram uma maior consistência no seu agrupamento. Para o estudo interespecífico, verificou-se que P. maliformis ficou em um grupo distinto, assim como P. giberti, mas próximo a $P$. mucronata. Para a espécie $P$. alata foi também verificada a sua alocação em um grupo distinto. Para as espécies $P$. cincinnata e $P$. edulis(Maracujá roxo), ambas ficaram alocadas em mesmo grupo, evidenciando uma proximidade entre as mesmas. As espécies $P$. foetida e $P$. suberosa formaram um grupo único.

Termos para indexação: Passiflora spp., melhoramento, resistência a doenças.

\section{GENETIC DIVERSITY AMONG YELLOW PASSION FRUIT COMMERCIAL GENOTYPES AND AMONG PASSIFLORA SPECIES USING RAPD}

\begin{abstract}
The genetic variability among yellow passion fruit genotypes was evaluated using RAPD as genetic markers of DNA. For that, genetic materials were collected in commercial populations from traditional production fields of the North Fluminense (Itaperuna, São Francisco do Itabapoana, Campos of Goytacazes, RJ-Brazil). The diversity among the cultivated species Passiflora edulis f. flavicarpa Deg. and species related $P$. alata, $P$. giberti, P. cincinnata, P. foetida, P. edulis. P. maliformis, P. mucronata, P. suberosa, P. malacophylla, was also estimated. For the study on yellow passion fruit, expressive genetic diversity was not verified; the populations were distributed according to its origin, and the individuals collected in São Francisco do Itabapoana presented major consistency in its grouping, once the formation of the groups a larger number of those individuals were allocated among the same group. For the interspecific study, it was verified that $P$. maliformis was in a different, but close group to $P$. mucronata. $P$. alata was allocated in an isolated group as well as $P$. giberti. For $P$. cincinnata and $P$. edulis (purple passion fruit), both were allocated in the same group, evidencing proximity between the same ones while $P$. foetida and $P$. suberosa formed a single group.
\end{abstract}

Index terms: Passiflora spp., breeding, variability, diseases resistance.

\section{INTRODUÇÃO}

As famílias das Passifloraceae apresentam um número expressivo de espécies, sendo o gênero Passiflora constituído por cerca de 530 espécies tropicais e subtropicais, das quais 150 são nativas do Brasil e cerca de 60 podem ser utilizadas na alimentação humana (Oliveira et al., 1994). O maracujá-amarelo (Passiflora edulis f. flavicarpa Deg.) e o maracujá roxo (Passiflora edulis) são as principais espécies cultivadas do gênero, sendo que a diferença entre as duas reside principalmente na coloração do fruto, sabor, características foliares e resistência às doenças (Martin \& Nakasone, 1970). As principais espécies do gênero são diplóides ( $2 \mathrm{n}=2 \mathrm{x}=18$ cromossomos), alógamas e auto-incompatíveis (Martin \& Nakasone, 1970).

A pesquisa sobre esta espécie é incipiente e a grande maioria refere-se ao manejo da cultura. Estudos de melhoramento genético normalmente visam ao desenvolvimento de materiais superiores com relação, principalmente, aos caracteres de interesse agronômico e tendem a utilizar a hibridação intra-específica para a transferência de genes de interesse (Bruckner, 1997). A hibridação interespecífica é também utilizada especialmente em programas que visam à transferência de genes de resistência a determinadas doenças encontradas nas espécies silvestres para a cultivada (Bruckner, 1997). Entretanto, tanto para o melhoramento intraespecífico quanto para o interespecífico, é necessário o conhecimento da variabilidade genética presente nas populações base.
Por se tratar de uma espécie semiperene, o estudo de diversidade genética em Passiflora spp. demanda tempo neste aspecto. Neste caso, o uso de marcadores moleculares é altamente viável, por permitir um rápido estudo da variabilidade presente (Stephen et al., 1997).

Alguns trabalhos foram conduzidos na caracterização de diversidade genética no gênero Passiflora, utilizando marcadores RAPD (Cassiano et al., 1998; Fajardo et al., 1998; Vieira et al., 1997).

Este trabalho teve como objetivo o estudo da diversidade genética entre genótipos de maracujazeiro amarelo e entre a espécie cultivada e algumas espécies silvestres, como forma de verificar as suas potencialidades para fins de melhoramento genético.

\section{MATERIALE MÉTODOS}

\section{Material genético}

No estudo da variabilidade dentro da espécie cultivada utilizou-se um total de 21 genótipos, coletados em populações comerciais de maracujá-amarelo na região Norte e Noroeste do Estado do Rio de Janeiro, e então propagados via estaquia e cultivados no campo, utilizando-se os tratos culturais recomendados por Carvalho (1998).

Para o estudo da variabilidade interespecífica, utilizou-se as espécies descritas na Tabela 01, cultivadas em casa de vegetação.

\footnotetext{
(Trabalho 117/2002). Recebido: 08/10/2002. Aceito para publicação: 11/09/2003. Financiado pela FAPERJ.

Professor Associado do Laboratório de Melhoramento Genético Vegetal - Universidade Estadual do Norte Fluminense-Campos dos Goytacazes-RJ-Cep: 28015620 - pirapora@uenf.br.

${ }^{3}$ Doutora em Produção Vegetal do Laboratório de Melhoramento Genético Vegetal - Universidade Estadual do Norte Fluminense-Campos dos Goytacazes-RJ-Cep: 28015-620.

${ }^{4}$ Pesquisador da Empresa de Pesquisa Agropecuária do Estado do Rio de Janeiro - PESAGRO-Macaé - RJ-Estrada Velha do Glicério- km 03, CX 119-371-Cep: 27901-970.
} 
TABELA 1 -Genótipos referentes às espécies e local de procedência das mesmas, utilizados neste trabalho.

\begin{tabular}{|c|c|c|c|}
\hline Genótipo & Espécie & Nome vulgar & Procedência \\
\hline 01 & P. edulis fflavicarpa & Marucujá Amarelo & São Francisco de Itabapoana \\
\hline 02 & P. edulis fflavicarpa & Marucujá Amarelo & São Francisco de Itabapoana \\
\hline 03 & P. edulis fflavicarpa & Marucujá Amarelo & São Francisco de Itabapoana \\
\hline 04 & P. edulis fflavicarpa & Marucujá Amarelo & São Francisco de Itabapoana \\
\hline 05 & P. edulis fflavicarpa & Marucujá Amarelo & São Francisco de Itabapoana \\
\hline 06 & P. edulis fflavicarpa & Marucujá Amarelo & São Francisco de Itabapoana \\
\hline 07 & P. edulis fflavicarpa & Marucujá Amarelo & São Francisco de Itabapoana \\
\hline 08 & P. edulis fflavicarpa & Marucujá Amarelo & São Francisco de Itabapoana \\
\hline 09 & P. edulis fflavicarpa & Marucujá Amarelo & São Francisco de Itabapoana \\
\hline 10 & P. edulis fflavicarpa & Marucujá Amarelo & São Francisco de Itabapoana \\
\hline 11 & P. edulis f flavicarpa & Marucujá Amarelo & São Francisco de Itabapoana \\
\hline 12 & P. edulis fflavicarpa & Marucujá Amarelo & Itaperuna \\
\hline 13 & P. edulis fflavicarpa & Marucujá Amarelo & Itaperuna \\
\hline 14 & P. edulis fflavicarpa & Marucujá Amarelo & Itaperuna \\
\hline 15 & P. edulis fflavicarpa & Marucujá Amarelo & Itaperuna \\
\hline 16 & P. edulis fflavicarpa & Marucujá Amarelo & Itaperuna \\
\hline 17 & P. edulis fflavicarpa & Marucujá Amarelo & Campos dos Goytacazes \\
\hline 18 & P. edulis fflavicarpa & Marucujá Amarelo & Campos dos Goytacazes \\
\hline 19 & P. edu lis fflavicarpa & Marucujá Amarelo & Campos dos Goytacazes \\
\hline 20 & P. edulis fflavicarpa & Marucujá Amarelo & Campos dos Goytacazes \\
\hline 21 & P. edulis fflavicarpa & Marucujá Amarelo & Campos dos Goytacazes \\
\hline 22 & P. foetida & Maracujá-catinga & EMBRAPA/CNPMF \\
\hline 23 & P. mucronata & Maracujá-pintado & Grussai \\
\hline 24 & P. alata & Maracujá-doce & Campos dos Goytacazes \\
\hline 25 & P. giberti & Maracujá-de-veado & Unesp/Jaboticabal \\
\hline 26 & P. suberosa & Maracujá-cortiça & Monte Alegre do Sul \\
\hline 27 & P. cincinnata & Maracujá-tubarão & IAC/Jundiaí \\
\hline 28 & P. maliformis & Maracujá-de-osso & IAC/Jundiaí \\
\hline 29 & P. edulis f. edulis & Maracujá-roxo & Campos dos Goytacazes \\
\hline 30 & Passiflora malacophylla & ------ & Rio das Ostras \\
\hline
\end{tabular}

\section{Caracterização molecular via RAPD}

A análise da divergência genética entre os genótipos foi feita com base na caracterização molecular, utilizando-se a técnica RAPD (RandomlyAmplified Polymorphic DNA).

As folhas foram coletadas em plantas individuais, tomadas ao acaso, amostrando-se cinco plantas de cada genótipo. A extração do DNA total foi efetuada conforme descrito por Fajardo et al. (1998), com algumas modificações. Para quantificar o DNA foi retirada uma amostra da solução de extração, e após diluição na proporção de $2 \mu \mathrm{l} / \mathrm{ml}$, foi realizada a leitura em fluorômetro. Após o isolamento e quantificação do DNA, foi procedida a amplificação em termociclador que foi realizada conforme preconizado por Willians et al. (1990) com modificações, e em seguida as etapas de eletroforese em gel de agarose, coloração e descoloração com brometo de etídio e visualização e arquivo de bandas com auxílio do "EAGLE EYE".

\section{Seleção de iniciadores}

A seleção de iniciadores realizou-se com três genótipos distintos: Passiflora edulis f. flavicarpa, Passiflora alata, Passiflora maliformis, de forma prévia, sendo testados 100 iniciadores da série OPERON Technologies, formando os seguintes grupos: OPAA 01-20, OPAB 01-20, OPAC 01-20, OPAD 01-20, OPAE 01-20.

\section{Análise dos dados}

Foi realizada a análise de agrupamento entre os genótipos, adotando-se o complemento do índice de Jaccard. Foi, também, empregado o método de agrupamento hierárquico de Ward com base na matriz de distâncias genéticas obtida do complemento do índice de Jaccard, sendo que os genótipos foram divididos em dois grupos: um grupo com as populações de maracujá amarelo e um segundo grupo com as espécies silvestres mais um genótipo médio. Esse genótipo médio representou os indivíduos de maracujá amarelo e foi obtido por meio da análise dos padrões de banda dos 21 genótipos de maracujá amarelo, sendo adotado o seguinte critério: quando a freqüência de presença de bandas foi maior ou igual a 0,5 , recebeu 1 na matriz de dados binários, e quando a freqüência de bandas foi menor do que 0,5 , atribuiu-se 0 na matriz binária. As análises estatísticas foram realizadas por meio do Programa GENES (Cruz, 2001).

\section{RESULTADOS E DISCUSSÃO}

\section{Ensaio de RAPD}

Com base nos resultados de polimorfismo, encontrou-se 63 iniciadores com algum polimorfismo (2-5 bandas) e 36 iniciadores com elevado polimorfismo (8-12 bandas), sendo que, para o estudo de 
diversidade, foram utilizados os 36 iniciadores com maior potencial. Os resultados foram reproduzidos por duas vezes utilizando-se os mesmos iniciadores.

$\mathrm{Na}$ diversidade interespecífica foi verificado elevado polimorfismo nos genótipos estudados, uma vez que o ensaio constou de materiais bem divergentes, visto que contou com várias espécies de maracujazeiro. Dos trinta e seis iniciadores utilizados, todos apresentaram bandas polimórficas, com média de 4,4 bandas por iniciador. Dos iniciadores utilizados, $22(68,75 \%)$ apresentaram quatro ou mais bandas. Do total de iniciadores, $31,25 \%$ apresentaram mais de cinco bandas por iniciador. Do total dos iniciadores, 37,5\% apresentaram entre 3 e 4 bandas e apenas dois (OPAC-08 e OPAC-10) apresentaram duas bandas.

Dos iniciadores com maior potencial para utilização em análise de marcadores RAPD no maracujazeiro, podem ser citados: OPAC-15, OPAC-20, OPAD-01, OPAD-11, OPAD-14, OPAD-16, OPAD-19, OPAE01, OPAE-08, OPAE-09, OPAE-10, OPAE-14, OPAE-18 e OPAE-19, os quais apresentaram pelo menos cinco ou mais bandas polimórficas.

Fajardo et al. (1998), trabalhando com espécies de Passiflora, utilizaram 50 iniciadores em 52 genótipos, que propiciaram um elevado polimorfismo entre as espécies e genótipos avaliados, gerando um total de 626 fragmentos polimórficos.

No estudo intra-específico pela análise de bandas no gel de agarose, observou-se baixo polimorfismo entre os indivíduos das populações de maracujá amarelo. Para os vinte e um genótipos, e, em todos os iniciadores utilizados, a amplificação foi muito semelhante (fenótipo eletroforético), tendo todos, um padrão de bandas semelhante e consistente. Esse tipo de resultado sugere que a grande variação morfológica observada em plantios comerciais de maracujá amarelo podem estar tendo uma grande influência ambiental.

\section{Análise de Divergência Genética}

No estudo intra-específico observou-se a formação de três grandes grupos (Figura 1) utilizando o método de agrupamento hierárquico de Ward. O grupo I conteve os genótipos 1, 3, 10, 11, 6 e 8, sendo observado subgrupos onde ficaram alocados os genótipos 1 e 3, 10 e 11 e 6 e 8. Todos esses genótipos foram coletados em São Francisco de
Itabapoana e advêm de populações desenvolvidas para cultivo em condições adversas, com utilização de baixo nível tecnológico, sendo, dessa forma, em geral, pouco produtivos.

No grupo II, verificou-se a inclusão dos genótipos 5, 7, 12, 14, 16, 18 e 20, reunindo portanto, genótipos coletados em São Francisco de Itabapoana, em Itaperuna e em Campos dos Goytacazes, denotando tratarem-se de genomas pertencentes a um mesmo grupo gênico. Quanto à produtividade, os indivíduos coletados em Campos dos Goytacazes e em Itaperuna são, em sua maioria, de melhor performance, dada às condições de cultivo. No primeiro caso, são indivíduos que passaram por um processo de melhoramento genético, podendo, dessa forma, apresentar um rendimento superior. No segundo caso, os indivíduos coletados em Itaperuna provêm de seleções feitas por produtores e cultivados em condições de bom nível de tecnologia, o que, de certa forma, favorece o predomínio de indivíduos que apresentem um elevado rendimento para algumas características. Por esta lógica, os genótipos 5 e 7, apesar de serem originários de São Francisco do Itabapoana, podem ser considerados materiais promissores já que estão agrupados junto com materiais submetidos a algum processo de melhoramento. Para o terceiro grupo, verificou-se a alocação dos genótipos 2, 4, 9, 13, 15, 17, 19 e 21. Nesse agrupamento há genótipos coletados em São Francisco de Itabapoana (2 e 4), Itaperuna (13 e 15) e Campos dos Goytacazes (17, 19 e 21), sendo que mais uma vez os genótipos de São Francisco de Itabapoana formaram um subgrupo distinto dos demais, possivelmente por seu frágil potencial produtivo.

No estudo interespecífico observou-se uma maior discriminação dos genótipos (Figura 2). Nota-se que os grupos começam a ser formados com uma elevada distância genética, o que caracteriza a expressiva diversidade existente entre os genótipos estudados (Vanderplank, 1991). As espécies do subgênero Passiflora foram divididas em dois grupos: o grupo I foi constituído pelo genótipo representativo das populações de maracujazeiro amarelo e pelas espécies $P$. malacophylla, P. maliformis, P. mucronata; o segundo agrupou as espécies $P$. alata, P. cincinatta e $P$. edulis f. edulis. O terceiro grupo reuniu as espécies $P$. foetida, P. suberosa e $P$. giberti que pertencem ao subgênero Dysomia, Plectostemma e Passiflora, respectivamente (Vanderplank, 1991).

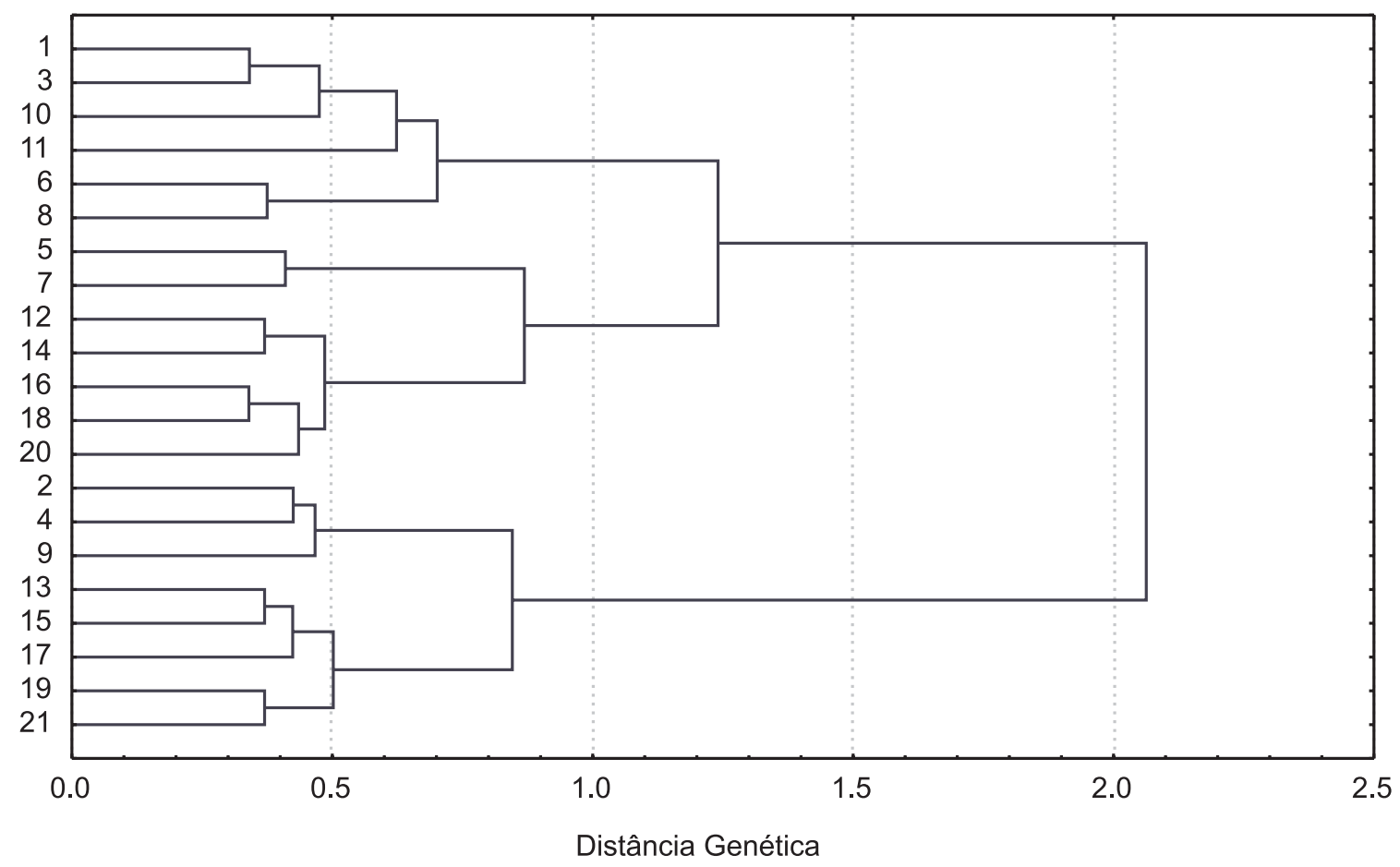

FIGURA 1 - Dendrograma de dissimilaridades genéticas entre genótipos de maracujazeiro (Passiflora edulis f. flavicarpa), obtido pelo método de Ward, com base na matriz de marcadores de DNA, utilizando-se o Complemento Aritmético do Índice de Jaccard. 


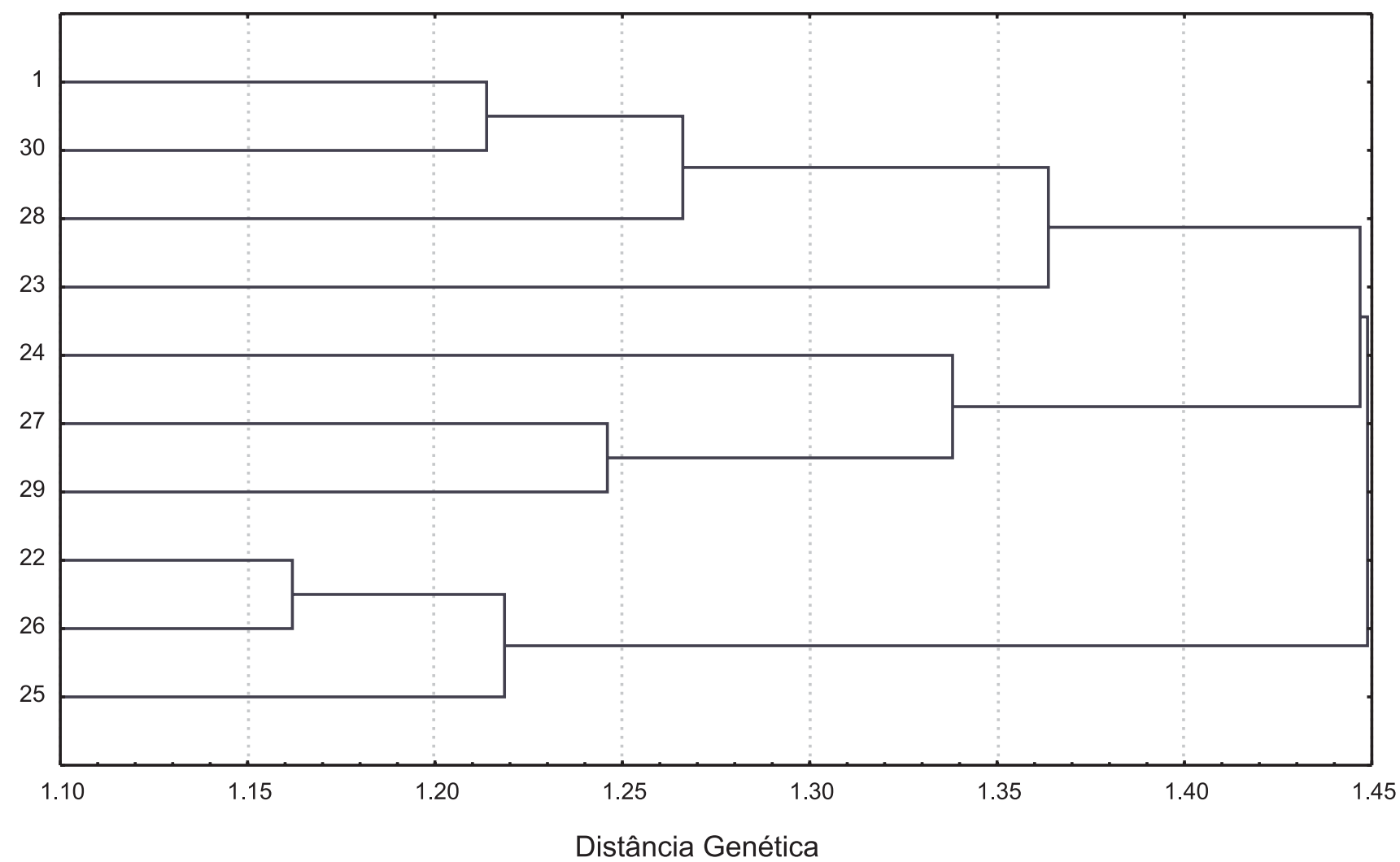

FIGURA 2 -Dendrograma de dissimilaridades genéticas entre Espécies do Gênero Passiflora (número 1 genótipo médio de maracujazeiro amarelo), obtido pelo método de Ward, com base na matriz de marcadores de DNA, utilizando-se o Complemento Aritmético do Índice de Jaccard.

As duas espécies cultivadas, maracujá amarelo e roxo, foram agrupadas separadamente, sugerindo a existência de considerável diversidade genética entre as mesmas, contrariando a hipótese de que o maracujá amarelo seria uma mutação do maracujá roxo ou um híbrido interespecífico natural entre o maracujá roxo e P. ligularis (Vanderplank, 1991). Estudos cromossômicos têm mostrado que apesar de haver um padrão consistente e característico para o gênero Passiflora, é possível detectar diferenças significativas entre as diferentes taxas analisadas; no caso das espécies cultivadas, maracujá roxo e amarelo, as características físicas dos cromossomos permitiram a distinção entre as duas (Mayeda, 1997).

Fajardo et al. (1998), utilizando marcadores RAPD, observaram uma grande variação intraespecífica em $P$. ligularis e $P$. adenopoda, enquanto que em $P$. edulis e P. maliformis houve pouca variação intraespecífica. Através desses marcadores eles obtiveram resultados que diferiram das classificações baseadas nos caracteres morfológicos, concluíram também que há uma elevada similaridade genética dentro entre $P$. vitifolia, $P$. spinosa e $P$. coriacea e entre $P$. xrosea e $P$. cumbalensis, $P$. pinnatitistipula e $P$. antioquiensis. Estes estudos servem de base para futuro estabelecimento de estratégias de melhoramento em espécies do gênero Passiflora.

Muschner et al. (1998) caracterizaram duas formas morfológicas de $P$. suberosa (normal e roxa) através de seqüências ITS1 e ITS2 ('internal transcribed spacers') do DNA ribossomal, sendo que os resultados revelaram a existência de grande variabilidade dentro da própria espécie, sugerindo uma tendência de agrupamento preferencial de indivíduos de uma mesma forma morfológica. Dos indivíduos estudados, três da forma normal não se relacionaram com nenhum dos grupos formados, não tendo sido detectados agrupamentos preferenciais por origem geográfica.

Vieira et al. (1997), pesquisando a variabilidade intraespecífica em Passifloras, via marcadores RAPD, encontraram bandas do tipo gênero-específicas e espécie-específicas. Foi obtida a freqüência de locos polimórficos e estimada a diversidade genética média com base em freqüências alélicas.
Cassiano et al. (1998) analisaram as espécies $P$. edulis, P. edulis f. flavicarp, $P$. amethystina, $P$. caerulea, $P$. cincinnata, $P$. coccinea, $P$. serrato-digitata, P. foetida, P. maliformis, P. alata, P. giberti, P. laurifólia, P. macrocarpa, P. nitida, P. setacea, P. suberosa, P. ligularis, P. capsularis e $P$. coriacea, através de marcadores tipo RAPD. Esses autores conseguiram caracterizar as espécies e relacionar a similaridade entre as mesmas. Os marcadores geraram informações sobre a diversidade genética e as relações filogenéticas no germoplasma usado, além de confirmarem a possibilidade da caracterização de híbridos.

A variabilidade é uma característica do gênero, considerando que algumas das espécies são alógamas, auto-incompatíveis e se cruzam com facilidade. A importância do estudo da variabilidade em Passiflora está em monitorar a hibridação interespecífica, visando a introgressão de genes das espécies silvestres para as cultivadas, além de definir quais as populações e espécies que poderão ser utilizadas em programas de melhoramento no Norte Fluminense.

\section{CONCLUSÕES}

Os genótipos de maracujazeiro amarelo seguiram um padrão de divergência consistente com o observado nos trabalhos de campo, mostrando a baixa variabilidade existente entre os indivíduos estudados, indicando que, para um programa de melhoramento com bons índices e ganhos satisfatórios, variabilidade adicional deve ser introduzida nas populações de estudo. Para as espécies estudadas, observou-se uma grande variabilidade, sendo que seu uso para programas de melhoramento deve ser explorado, principalmente em hibridações visando resistência às doenças da cultura.

\section{REFERÊNCIAS BIBLIOGRÁFICAS}

BRUCKNER, C.H. Perspectivas do melhoramento do maracujazeiro. In: Manica, I. (Ed). Maracujá: temas selecionados. Porto Alegre, RS: Cinco Continentes, 1997. 70p. 
CARVAlHO, A. J. C. C. O cultivo do maracujazeiro, Campos dos Goytacazes, RJ: UENF. 2000. 45p.

CASSIANO,A. P. A. A.; LEMOS, E.G.M.; OLIVEIRA, J.C., Avaliação de espécies de Passiflora através de marcadores moleculares RAPD. Genetics and Molecular Biology, v.21, n.3, p.214, 1998. Suplemento.

CRUZ, C.D. Programa Genes (Versão Windows): Aplicativo computacional em genética e estatística. Viçosa: Editora UFV, Universidade Federal de Viçosa, 2001. 648p.

ANGEL, F. O.; FAJARDO, D.; GRUM, M.;TOHME, J.; LOBO, M.; Genetic variation analysis of the genus Passiflora L. using RAPD markers. Euphytica, Dordrecht, v.101: p. 341-347, 1998.

MARTIN, F.W.; NAKASOME, Y.The edible species of passiflora. Economic Botany, Bronx, v.24, n.3, p. 333-343.1970.

MAYEDA, L.Y. Estudos Citogenéticos em Dez Táxons do Gênero Passiflora L. Piracicaba. 89f. Dissertação (Mestrado em Agromomia) - Escola Superior de Agricultura “Luiz de Queiroz”, Universidade de São Paulo, Piracicaba, 1997.

MUSCHNER, V. C.; FREITAS, L. B.; SOUZA-CHIES, T. T.; SALZANO, F. M., Análise fillogenética das seqüências ITS1 e ITS2 em duas formas morfológicas de Passiflora suberosa (Passifloraceae).
Genetics and Molecular Biology, v.21 n.3, p. 270, 1998. Suplemento. OLIVEIRA, J.C.; NAKAMURA, K.; MAURO, A.O.; CENTURION; M.A.P.C. Aspectos gerais do maracujazeiro. In: São José, A.R. (Ed.) Maracujá: produção e mercado. Vitória da Conquista: Universidade Estadual do Sudeste da Bahia, 1994, p.27-37.

STEPHEN, K.; MCFERSON, J.R.;WESTMAN, A.L. Using molecular markers in genebanks: identify, duplication, contamination and regeneration, Analysis, Characterization and Conservation of PGR. 1997, 16p.

VANDERPLANK, J. Passion flowers and passion fruit. London: 1991.175p.

VIEIRA, M.L.C.; OLIVEIRA, C.A.; MAYEDA, L.Y.; DORNELAS, M.C.; FUNGARO, M.H.P. Estudo do cariótipo e da variabilidade genética detectada por RAPD em espécies de maracujazeiro (Passiflora L.). Brazilian Journal of Genetics, Ribeirão Preto, v.20, n.3, p. 88, 1997. Suplemento.

WILLIAMS, J.G; KUBELIK, A.R.; LIVAK, K.J.; RAFALSKI, L.A.; TINGEL, S.V. DNA polymorphism amplified by arbitrary iniciator are useful as genetic markers. Nucleic Acids Research, v.18, p.65316535,1990 . 